\title{
Endocrine Therapy in Older Women with Early-Stage Hormone Sensitive Breast Cancer
}

Tina Hsu* and Shelly Sud

Department of Medical Oncology, The Ottawa Hospital Cancer Centre, 501 Smyth Rd, Ottawa ON K1H 8L6, Canada

\begin{abstract}
Breast cancer is the most common cancer affecting women worldwide, with the highest risk in those aged 70 and over. Most older women ( $80 \%$ to $85 \%$ ) have hormone receptor positive breast cancer and thus the use of endocrine therapy is common in this population. Typically, women receive endocrine therapy for at least 5 years to reduce the risk of cancer recurrence and decrease breast-cancer mortality. However, adherence to hormonal therapy may be an issue, particularly in older women, as side effects may lead to early discontinuation and/or non-adherence. Older women on endocrine therapy are often cared for by primary care physicians and geriatricians and therefore, an understanding of oral endocrine therapy, as well as its potential side effects, is essential for treating physicians. This review describes the benefits of endocrine therapy in patients with resected breast cancer, compare different hormonal therapies with regards to side-effects and discuss management strategies with a particular focus on the concerns of older breast cancer patients on endocrine therapy. Mrs. Smith is a 75-year-old woman whose family doctor noted a $3 \mathrm{~cm}$ to $4 \mathrm{~cm}$ lump in her left breast during a routine physical exam. She has no palpable lymph nodes. Her family doctor sends her for a mammogram which reveals a $2.6 \mathrm{~cm}$ spiculated mass in the left upper outer quadrant. Biopsy reveals an invasive ductal carcinoma.
\end{abstract}

Keywords: Breast cancer; Endocrine therapy; Sensitive; Early stage

\section{Introduction}

Breast cancer is the most common cancer affecting women worldwide with an estimated 1.6 million cases diagnosed in 2012 [1]. In the United States, 1 in 8 women will develop breast cancer in their lifetime with women age 65 and over accounting for $41 \%$ of all newly diagnosed breast cancer and almost $60 \%$ of all breast cancer deaths [2]. The risk of developing breast cancer increases with age, with the highest risk in those age 70 and over [3].

Older women are more likely to have more advanced disease at diagnosis [4-6]. However, tumors in older women are more likely to have more favourable biology, including higher rates of hormone receptor positivity, lower rates of HER-2 positivity, lower rates of proliferation, and a lower frequency of p53 accumulation [4,5,7-10]. Despite more favourable tumor biology, increasing age is associated with a higher risk of death from breast cancer [4], potentially due to under-treatment which is more common with increasing age $[11,12]$.

Many older women receive adjuvant endocrine therapy due to the high proportion of hormone receptor positivity (80\% to $85 \%$ ) [4], more favourable toxicity profile, and limited evidence supporting chemotherapy use in women age 70 and over due to their underrepresentation in clinical studies [13]. With the increasing prevalence of breast cancer combined with 5-year survival rates of close to $90 \%$ [2], primary care physicians and geriatricians are increasingly relied upon to see and manage patients receiving these therapies [14]. This is particularly true in patients age 80 and over [15]. Thus, a better understanding of the potential risks and benefits are necessary.

Mrs. Smith is referred to a surgeon. The surgeon notes that she has a history of hypertension, Type II diabetes mellitus, and osteoarthritis. Her medications include hydrochlorothiazide, metformin, and vitamin D. She is independent in her activities of daily living, as well as her instrumental activities of daily living. Her ECOG PS is 0. She lives at home with her husband who has Alzheimer's disease, and for whom she is the primary caregiver. They live in a two-story home, and rely on their daughter who lives nearby for support.

The surgeon discusses the option of lumpectomy with radiation or mastectomy. She is hesitant to have surgery because she is concerned about who would care for her husband while she is recovering. The surgeon requests receptor status to be done and she is found to be ER/PR positive, HER-2/neu negative.

\section{Treatment of Early-Stage Breast Cancer}

Standard treatment for localized breast cancer involves definitive surgical excision, either with mastectomy or with breast-conserving therapy and radiation. Older women, however, are less likely to have surgery than younger women with breast cancer $[6,16]$. For women with hormone sensitive disease, primary treatment with endocrine therapy alone is an option. One study suggests that up to $42 \%$ of women, age 70 and over, are treated with endocrine therapy alone. A Cochrane review of women, 70 years of age and over, with operable breast cancer found that although there was no difference in overall survival in those treated with surgery vs. primary endocrine therapy, that surgery provided better local control with less risk of local complications [17].

Primary endocrine therapy can provide disease control for 2 years to 3 years, so is an option for patients with hormone sensitive breast cancer with a life expectancy of $<2$ years, who are unfit, or who refuse definitive surgical resection $[17,18]$. Generally, however, most women with localized breast cancer should be offered surgical resection for localized breast cancer irrespective of age.

Mrs. Smith meets with the medical oncologist. Reviewing her function and comorbid conditions, the oncologist discusses that she has an estimated average life expectancy of 12 years. The oncologist suggests that Mrs. Smith should have surgery because this would decrease the

${ }^{*}$ Corresponding author: Tina Hsu, Department of Medical Oncology, The Ottawa Hospital Cancer Centre, 501 Smyth Rd, Ottawa ON K1H 8L6, Canada. Tel: (613) 737-7700; E-mail: thsu@toh.on.ca

Received July 13, 2017; Accepted July 18, 2017; Published July 22, 2017

Citation: Hsu T, Sud S (2017) Endocrine Therapy in Older Women with EarlyStage Hormone Sensitive Breast Cancer. J Gerontol Geriatr Res 6: 440. doi:10.4172/2167-7182.1000440

Copyright: @ 2017 Hsu T, et al. This is an open-access article distributed under the terms of the Creative Commons Attribution License, which permits unrestricted use, distribution, and reproduction in any medium, provided the original author and source are credited. 
likelihood of local complications in the future. Her daughter offers to move in with her parents to help during the post-operative period.

Mrs. Smith proceeds with a mastectomy and sentinel lymph node biopsy. She recovers well with no complications. Pathology reveals a $2.2 \mathrm{~cm}$ grade $2 \mathrm{ER} / \mathrm{PR}$ positive, HER-2/neu negative invasive ductal carcinoma. There is cancer in two of two lymph nodes. Margins were negative.

She returns to meet with the medical oncologist to discuss the need for further treatment.

\section{Adjuvant Endocrine Therapy}

Following definitive local therapy, additional systemic therapy may be indicated to decrease the risk of breast cancer recurrence and potentially breast cancer related death. The benefit of adjuvant systemic treatment depends on the risk of recurrence, which is based on the characteristics of the breast cancer (size, lymph node involvement, hormone receptor and HER-2 status) and the patient's risk of noncancer related mortality. A thorough and accurate assessment of the patient's health and overall life expectancy is important in this decisionmaking process, a skill set geriatricians are adept at.

In the general breast cancer population, adjuvant endocrine therapy is recommended in most patients with early stage hormone sensitive breast cancer $[18,19]$. In patients with tumors smaller than $0.5 \mathrm{~cm}$ and no lymph node involvement, or those who have significant comorbidity, adjuvant endocrine therapy may potentially be omitted as the magnitude of benefit in this population is small $[8,10,19]$.

The benefit of adjuvant endocrine therapy was demonstrated in a large meta-analysis by the Early Breast Cancer Trialists' Collaborative Group (EBCTCG), which demonstrated a 39\% decrease in breast cancer recurrence, $40 \%$ decrease in contralateral breast cancer, and a $30 \%$ decrease in breast cancer mortality, with the use of tamoxifen for 5 -years compared to surgery alone [20]. A benefit was observed both in younger and older women. Recent studies suggest an additional benefit of continuing tamoxifen for 10 years [21]. However, relatively few women ages 70 and over (9\%) were included [21].

Aromatase inhibitors (AI), a newer class of endocrine agents, have been shown to decrease the risk of breast cancer recurrence by a further $15 \%$, and contralateral breast cancer by $40 \%$ [22-25]. In women, age 70 and over, who have completed 5-years of tamoxifen, an additional 5-years of an AI demonstrated a further decrease in breast cancer recurrence compared to placebo with no differences in QOL and toxicity compared to their younger counterparts [26]. The current recommendation is that all women receive an $\mathrm{AI}$ as a component of their adjuvant endocrine therapy, either upfront for 5-years, in sequence after 2 years to 3 years of tamoxifen for up to 5 -years, or in sequence after 5-years of tamoxifen for another 5-years of therapy [19] (Table 1). The choice of upfront AI versus a switch strategy is often determined by the overall risk of breast cancer recurrence, as well as toxicity profile of the drug. Recent studies suggest that ten years of aromatase inhibitors may decrease local breast cancer recurrences [27] with one study demonstrating a decreased risk of distant metastases [28]. Other studies however have been negative $[29,30]$ and no studies have yet to show an improvement in overall survival with 10 years of AI treatment. Ten years of AI can be considered in selected women with high risk of breast cancer recurrence with a reasonable life expectancy who are tolerating AI well. In women who cannot receive or decline to receive an AI, 5 -years and potentially 10 -years of tamoxifen is an acceptable alternative.

\section{No contraindications to aromatase inhibitors}

Tamoxifen $\times 2$ years to 3 years $\rightarrow$ Aromatase inhibitor to complete 5 years Aromatase inhibitor $\times 2$ years to 3 years $\rightarrow$ Tamoxifen to complete 5 years Aromatase inhibitor $\times 5$ years

Tamoxifen $\times 5$ years $\rightarrow$ aromatase inhibitor $\times 5$ years

Aromatase inhibitors $\times 10$ years

Contraindication to aromatase inhibitor or patient refusal

Tamoxifen $\times 5$ years. May consider tamoxifen for up to 10 years

Table 1: Acceptable endocrine therapy strategies in older women.

\section{Considerations in Older Women}

Increased age alone should not preclude adjuvant systemic therapy. This is important as older women, particularly those $>70$ years of age, are at high risk of under-treatment, which can result in increased rate of recurrence (HR 1.21) and breast cancer mortality [31]. Although increasing age is associated with a higher risk of death from non-cancer causes (HR 4.13) [31] and thus proportionally less deaths related to breast cancer, the absolute proportion of breast cancer related deaths, even in those 85 and older, is still significant (29\%) [32].

Advanced age is associated with an increased burden of comorbid conditions, with $40 \%$ patients 80 years and older having one or more comorbid conditions [33]. Increasing burden of comorbid conditions is strongly associated with a higher risk of death from non-cancer related causes with those women who have 3 or more comorbidities (using the Satariano score) at a 20 fold increased risk of death from non-cancer related causes [16]. Similarly, patients with functional impairment in at least one domain, more commonly observed in older adults, have been found to have an increased risk of overall mortality and death from non-breast cancer related causes [34]. Although there is a higher prevalence of comorbid conditions with increasing age, endocrine therapy use is similar in older and younger women [32].

\section{Drug Metabolism and Drug-Drug Interactions}

Tamoxifen is a selective estrogen receptor modulator (SERM), which competitively inhibits the estrogen receptor in the breast. Tamoxifen is a pro-drug that undergoes metabolism by the hepatic cytochrome $\mathrm{P} 450$ system, specifically CYP2D6 and CYP3A4/5, to produce endoxifen, the primary active metabolite [35].

Almost 100 variants of CYP2D6 have been reported [36]. Patients with CYP2D6 polymorphisms associated with poor/intermediate activity, metabolize tamoxifen less effectively resulting in reduced levels of endoxifen [37]. Some retrospective studies have suggested that these patients have a higher risk of breast cancer recurrence and an increased risk of breast cancer mortality, while others found no difference in breast cancer outcomes or overall survival [38-41]. Increased age is associated with increased plasma levels of endoxifen and other tamoxifen metabolites [42,43]. The clinical significance of this is unknown, however, and there is currently no evidence to suggest that older women should receive lower doses of tamoxifen, or that lower doses of tamoxifen are as effective as standard doses in preventing breast cancer recurrences. Currently CYP2D6 genotype testing is not routinely recommended in breast cancer patients initiating tamoxifen [44].

Many drugs inhibit CYP2D6 function. Polypharmacy is common in older adults with cancer who take an average of six prescription medications [45]. It is unclear whether concomitant use of CYP2D6 inhibitors with tamoxifen affects breast cancer outcomes. Some studies suggest that co-prescription of CYP2D6 inhibitors increases the risk of breast cancer recurrence and associated death [46,47], while other studies have not noted this association [48]. Nevertheless, it 


\begin{tabular}{|c|c|}
\hline \multicolumn{2}{|c|}{ CYP 2D6 } \\
\hline Moderate-potent inhibitors & Weak-moderate inhibitors \\
\hline Paroxetine & Amitryptilline \\
\hline Fluoxetine & Nortryptilline \\
\hline Bupropion & Haldol \\
\hline Thioridazine & Verapamil \\
\hline Perphenazine & Nifedipine \\
\hline Pimozide & Cimetidine \\
\hline Quinidine & Sertraline \\
\hline Ticlopidine & \\
\hline Terbinafine & \\
\hline
\end{tabular}

Table 2: Common inhibitors of CYP2D6.

is recommended that moderately-potent inhibitors of CYP2D6 be avoided if possible in women on tamoxifen [48] (Table 2). While there is no clear recommendation regarding weak to moderate inhibitors of CYP2D6, an alternative option should be considered when possible [48].

Drug interactions may also occur between tamoxifen and warfarin. Several case reports indicate that tamoxifen may increase the risk of bleeding complications while on warfarin $[49,50]$ and as such it is advisable to closely monitor the INR in patients receiving warfarin and adjust the dose if required [51].

Aromatase inhibitors (AI) are another class of oral endocrine agents. Peripheral conversion of circulating androgens to estrogen by the enzyme aromatase forms the primary source of estrogen in post-menopausal women [52]. AI inhibit aromatase, thus reducing circulating levels of estrogen and inhibiting cell growth. Despite metabolism by $\mathrm{P} 450$ enzymes, there is no significant drug-drug interaction with commonly prescribed drugs that requires monitoring or caution [53].

\section{Side Effects}

Although AI are associated with a slight decrease in the risk of breast cancer recurrence compared with tamoxifen, the choice of endocrine agents is often influenced by differences in their side effect profiles. Both tamoxifen and AI are associated with side effects related to estrogen derivation including vasomotor symptoms such as hot flashes. The prevalence of hot flashes in tamoxifen users ranges from $40 \%$ to $70 \%$ [54-57], while AI may be associated with fewer hot flashes (36\% to $38 \%$ ) [25,58]. Genitourinary side effects that are common include vulvovaginitis, vaginal dryness or non-infectious discharge, and urinary incontinence [58,59].

Other more significant side-effects stemming from tamoxifen's estrogen agonist effect on the uterus includes an increased incidence of endometrial cancers in post-menopausal women (from $0.2 \%$ to $0.8 \%$ ) [58]. Though the frequency of endometrial cancer remains low after 5 years of tamoxifen use, it nearly doubles $(3.1 \%)$ when use is prolonged to 10 years [21].

There is a significant increase in the relative risk of thromboembolic events such as pulmonary embolism and strokes during tamoxifen use [60]. Data from adjuvant trials using tamoxifen confirm increased rates of venous-thromboembolic events (1.9\% to $4.5 \%)$ [54,58]. Nevertheless, tamoxifen may have a protective effect with respect to some cardiac risk factors, as it is noted to reduce levels of low-density lipoprotein (LDL) [61]. Unlike tamoxifen, AI have no pro-estrogenic effects and as a result have a lower incidence endometrial cancer $(0.2 \%$ vs. $0.8 \%)$ and venous thromboembolic events ( $2.4 \%$ to $2.8 \%$ vs. $4.1 \%$ to $4.9 \%$ ) [25,58].

The most of troublesome side effects of $\mathrm{AI}$ is the presence of musculoskeletal symptoms, including arthralgias, myalgias, and bone pain. Clinical trials indicate that about one third of women experience arthralgias $[25,58]$. In clinical practice, however, up to $60 \%$ of women taking AI report arthralgias or bone pain, with 30\% characterizing their symptoms as severe and $20 \%$ discontinuing $\mathrm{AI}$ as a result [62]. AI-induced arthralgias (AIA) can be associated with morning stiffness and myalgias and typically start a median of 1.6 month after starting treatment (range weeks to $>1$ year), peaking at 6 months [63]. The risk of AIA is higher in patients who are obese, have baseline osteoarthritis or arthralgias, have received chemotherapy or have used hormone replacement therapy in the past $[64,65]$.

AI are also associated with an increased incidence of osteoporosis $(\sim 33 \%)$ and fractures $(\sim 10 \%)$ compared to tamoxifen $[25,58,66]$. However, this risk appears to abate after discontinuation of AI [67]. Exemestane may be associated with a slightly lower incidence of osteoporosis compared to anastrozole [66]. Tamoxifen has an agonist effect on the bone resulting in a noted reduction in osteoporotic fractures during its use [68].

Given the involvement of multiple lymph nodes and Mrs. Smith's good functional status, the medical oncologist recommends that Mrs. Smith receive further treatment with endocrine agents. They discuss the option of tamoxifen vs. aromatase inhibitors. Mrs. Smith is concerned about developing arthralgias from an aromatase inhibitor given her pre-existing issues with osteoarthritis. Mrs. Smith agrees to a trial of tamoxifen.

Mrs. Smith makes an appointment to see her family doctor after being on tamoxifen for six months. She complains of significant hot flashes that are preventing her from sleeping. She is complaining of moderate fatigue that is impacting her ability to concentrate and she admits to skipping her medications at times.

\section{Management of Side Effects of Tamoxifen and AI}

\section{Vasomotor symptoms}

Vasomotor side effects are common with the use of oral endocrine agents. Non-pharmacological strategies such wearing lighter clothes, decreasing the room temperature, avoidance of noted triggers or changing the timing of medication use may help ameliorate some symptoms. Relaxation training and cognitive behavioural therapy has been found to reduce the incidence and severity of hot flashes in some studies $[69,70]$. Other non-pharmacologic interventions, such as exercise, have not been shown to improve vasomotor symptoms $[70,71]$.

Hormone Replacement Therapy (HRT) has long been used to help ameliorate menopausal symptoms in women, though this practice has dropped dramatically since the reporting of the results of the women's health initiative. However, in women with hormone receptor positive breast cancer receiving endocrine therapy, there is naturally a concern about the association of HRT with an increased risk of breast cancer [72]. For this reason, non-hormonal pharmacologic agents are generally preferred (Table 3 ).

SSRI=serotonin selective reuptake inhibitor; $\mathrm{SNRI}=$ serotonin norepinephrine reuptake inhibitor

${ }^{* *}$ Potent inhibitor of CYP2D6-consider avoiding in patients on tamoxifen

Multiple studies and two systematic reviews found that selective serotonin reuptake inhibitors (SSRIs), such as paroxetine and citalopram, and serotonin norepinephrine reuptake inhibitors (SNRIs), such as venlafaxine, decrease vasomotor symptoms in patients with 


\begin{tabular}{|c|c|}
\hline Class & Effective Dose \\
\hline SSRI/SNRIs & Initial dose $37.5 \mathrm{mg} / \mathrm{d}-$ titrate to $75 \mathrm{mg} / \mathrm{d}$ after \\
\hline Venlafaxine & 1 week if needed \\
\hline Paroxetine ${ }^{* *}$ & $10 \mathrm{mg} / \mathrm{d}$ \\
\hline Citalopram & $10-20 \mathrm{mg} / \mathrm{d}$ \\
\hline Gabapentin Pre-gabalin & $\geq 900 \mathrm{mg} / \mathrm{d} 75 \mathrm{mg}$ BID \\
\hline Clonidine & $0.1 \mathrm{mg} / \mathrm{d}$ \\
\hline
\end{tabular}

Table 3: Non-hormonal pharmacologic options for management of vasomotor symptoms.

breast cancer compared to placebo [73-75]. In patients on tamoxifen, however, avoidance of moderately-potent inhibitors of CYP2D6 such as paroxetine and fluoxetine (Table 2), which may decrease the efficacy of tamoxifen, should be avoided if possible. Gabapentin, pregabalin, and clonidine also decrease the frequency and severity of hot flashes compared to placebo $[73,74,76-78]$ and are also reasonable options.

Comparing non-hormonal agents, one systematic review concluded that venlafaxine and paroxetine appeared to be most effective of the SSRIs/SNRIs [74]. In head-to-head studies, venlafaxine, gabapentin, and clonidine appear to reduce hot flash scores to a similar degree $(33 \%$ to $66 \%)[74,79,80]$. Patient comorbidity and drug side effect profiles may dictate selection of agents, though one study found that $2 / 3$ of patients preferred venlafaxine over gabapentin [79].

Lastly, switching from one hormonal agent to another (i.e., from tamoxifen to an AI, or between $\mathrm{AI}$ ) may help alleviate vasomotor symptoms in some women and is an option if the above strategies are ineffective.

\section{Vulvovaginal symptoms}

Vulvovaginal symptoms, such as dryness, are common in women on endocrine therapy affecting almost $50 \%$ of women on endocrine therapy, particularly those on AI [81]. Potential vaginal irritants such as scented toilet paper, soaps and fabric softeners, as well as synthetic garments should be avoided [59,82]. Regular sexual activity may help promote blood flow to the area improving vaginal atrophy [83]. Localized treatment with vaginal moisturizers, such as Vagisil and Replens, as well as the use of lubricants during intercourse may help alleviate symptoms $[59,84]$.

Vaginally delivered low dose estrogen therapy improves symptoms of vulvovaginal atrophy and can result in an improvement in quality of life $[85,86]$. However, it is absorbed systemically to some extent and has been shown to increase serum estradiol levels to variable degrees $[86,87]$. This raises some concerns about the safety of vaginal estrogens in patients with breast cancer, particularly in patients on AI though the clinical implications of this increase in estrogen on breast cancer outcomes is unclear $[82,86]$. No increased risk of breast cancer recurrence was observed in a small cohort study $(n=69)$ of women with breast cancer receiving topical vaginal estrogen [88]. Some suggest that vaginal estrogen therapy can be considered after a discussion of risks and benefits with the patient, particularly as vaginal symptoms that are not well controlled can potentially result in non-compliance or early discontinuation [59]. If utilized, consideration of vaginal estrogens with lower levels of systemic estrogen uptake should be considered [87]. Tamoxifen is associated with less vulvovaginal atrophy and dryness due to its weak pro-agonistic effect on the vagina and changing from an $\mathrm{AI}$ to tamoxifen is also a reasonable alternative strategy.

\section{Endometrial cancer}

Although tamoxifen is associated with a higher risk of endometrial cancer, there is currently no indication for routine screening of patients with either transvaginal ultrasound or endometrial biopsies $[89,90]$. However, it is important to counsel patients to report any vaginal bleeding [90]. The American College of Obstetricians and Gynecologists recommends that post-menopausal women be thoroughly investigated when presenting with vaginal bleeding, and that tamoxifen be reassessed upon development of atypical hyperplasia [91].

\section{Bone loss}

Bone loss associated with AI use can have significant implications for older women as consequent fractures may lead to hospitalization, disability and institutionalization [92]. Patients receiving AI therapy should have baseline bone mineral density testing and this should be repeated regularly $[19,93,94]$. Patients should be counseled on established strategies to prevent bone loss including regular exercise, calcium and vitamin D supplementation, and smoking cessation, as well as recommendations to prevent falls including regular strength and balance training and reduce the use of psychotropic medications [95]. Bisphosphonates are indicated as dictated by current osteoporosis management guidelines [93]. The utilization of a switch strategy using tamoxifen initially may help mitigate the effects of subsequent use of AI [94].

\section{Arthralgias}

Educating patients about $\mathrm{AI}$ associated musculoskeletal side-effects before treatment initiation and assessing their baseline pain level due to pre-existing conditions is essential to optimally assess for the onset of AI-induced arthralgias (AIA) [96]. Initial management for AIA includes lifestyle modification such as weight loss, exercise, massage therapy, and physiotherapy $[97,98]$. Randomized studies of an exercise intervention and another using acupuncture have shown a reduction in the severity of pain from AIA $[99,100]$. While these studies are promising, further validation of these strategies are required.

If AIA are refractory to conservative management, pharmacologic intervention such as acetaminophen should be considered. Although non-steroidal anti-inflammatory drugs (NSAIDs) are an option [97,101], they should be used cautiously in older adults. If symptoms persist tramadol, low dose narcotics or intra-articular injections may be considered [97,102,103]. Co-analgesics, such as tricyclic antidepressants and gabapentin, can also be considered in conjunction with analgesia [97].

If AIA do not improve with non-pharmacologic interventions or analgesics switching to a different AI or to tamoxifen may be helpful. While comparisons of AI have demonstrated similar rates of arthralgia $[66,104]$, some evidence suggests that some patients may benefit from a switch to another AI [105]. Switching to tamoxifen, which is associated with a lower rate of arthralgias ( $29.4 \%$ vs. $35.6 \%)$ [58], is also an option.

\section{Adherence with Adjuvant Endocrine Therapy}

As with any oral medication, efficacy of the treatment depends on patient adherence to the prescribed medication. This is a particularly relevant issue in older adults, who are often on multiple medications due to the presence of comorbid conditions and are at higher risk of cognitive impairments [106-108].

In patients prescribed endocrine therapy in the adjuvant setting, studies indicate that $13 \%$ to $42 \%$ do not start treatment [15,109-111], with higher values reported in studies which checked prescription refills, rather than by self-report $[15,107,108]$. One study found that women who were older at diagnosis (age 80 or older) were less likely to initiate therapy while another found that older women were more 
likely to fill the initial prescription [15,108]. Another study found women who were frail or pre-frail were more likely to not initiate recommended endocrine therapy $[15,111]$. This may be because women who are frailer have a higher risk of non-cancer related death with prior studies showing that women with a Satariano comorbidity index of $2+$ have a $4.2 x$ to $20 \mathrm{x}$ increased risk of death without recurrence $[10,112]$. Increased age alone, however, should not be a reason not to initiate or continue adjuvant endocrine therapy as older women, particularly those 80 and over, are at high risk of under-treatment, which has been shown to result in increased breast cancer mortality [10-12].

Of women who initiate adjuvant endocrine therapy, early discontinuation of treatment prior to the completion of 5-years is common, ranging from $25 \%$ to $73 \%[15,109,111,113-118]$. Even in those patients who continue with endocrine therapy, only $60 \%$ to $81 \%$ of women are considered adherent (defined as having medication for at least $80 \%$ of the days) $[109,110,114,116,119,120]$. The rate of early discontinuation is highest in the first year (15-32\%) with a rate of discontinuation of about $10 \%$ annually in subsequent years $[9,109,118]$.

Older women may be at a particularly high risk of early discontinuation and non-adherence. Increasing age, especially age greater than 75 years or 85 years old, has been associated with both early discontinuation and non-adherence [15,108,109,111]. Furthermore, multi-morbidity and polypharmacy (>15 medications), which are common in this population, are also associated with an increased risk $[109,115-117,120]$. One study found that an increase in comorbid conditions (HR 1.52) or cardiopulmonary comorbidities (HR 1.75) 3-years after breast cancer diagnosis, compared to at the time of breast cancer diagnosis, was predictive of early discontinuation of endocrine therapy, potentially indicating a decision by patients or physicians to stop treatment due to an increased risk of non-cancer mortality [117]. This was suggested in another study in which adjuvant endocrine therapy was discontinued more commonly by physicians in women age 80 and over, compared to women age 60-79, due to serious medical reasons not related to breast cancer ( $17 \%$ vs. $4.7 \%, \mathrm{p}=0.003$ ) [15]. Interestingly, being frail at diagnosis was not found to be predictive of early discontinuation [111].

Women who do not receive chemotherapy $[109,113]$ or radiation [109], more commonly seen with increasing age, are also at higher risk of non-adherence. Early discontinuation and non-adherence can be especially concerning in women who have had breast conserving therapy but have not received any breast irradiation [117]. Omission of radiation is an acceptable strategy in some women $>70$ years old with small node-negative hormone sensitive tumors receiving endocrine therapy, as studies suggest no survival disadvantage, though there is a higher risk of local recurrence $[121,122]$. This, however, is in the context of endocrine therapy and thus adherence with endocrine therapy is particularly important in this subset of women. In fact, it has been shown that mortality is higher in women who discontinue hormonal therapy early (HR 1.49; 10-year survival $73.6 \%$ vs. $80.7 \%$, $\mathrm{p}<0.001$ ), as well as in those who are non-adherent with endocrine therapy (HR 1.25 ; 10 -year survival $77.8 \%$ vs. $81.7 \%$, $\mathrm{p}<0.001$ ) [113].

Discontinuations within 12 months of initiation are more often due to the presence of intolerable adverse effects compared to late discontinuations (43\% vs. $24 \%)$ [15,117]. Thus, addressing side effects such as hot flashes and arthralgias (as discussed above) and/ or considering a switch from one agent to another (i.e., tamoxifen to aromatase inhibitor or vice versa), may help improve compliance. Financial factors, such as amount of copayment and household income may also influence non-adherence and premature discontinuation of endocrine therapy $[109,116,118,120]$. Prescription of generic forms of endocrine therapy may be one method to help improve patient compliance [116].

Mrs. Smith's doctor reviews the rationale for tamoxifen and emphasizes the importance of taking it on a regular basis. They discuss non-pharmacological methods to manage her hot flashes. Mrs. Smith says that she is already wearing light clothing and using a fan at night. They discuss the possibility of starting her on venlafaxine to help her symptoms and she is amenable to trying it.

Mrs. Smith starts on a low dose of venlafaxine. On follow-up with her family doctor 6 weeks later she notes a slight improvement in her hot flashes. Her family increases the dose of venlafaxine. On subsequent follow-up Mrs. Smith reports a marked improvement in her hot flashes. She reports no difficultly with taking her medication and states she is taking all her medication on a daily basis.

\section{Conclusion}

In summary, breast cancer is common in older women and most have hormone sensitive disease. Surgical resection should be offered as a standard to most women with localized disease regardless of age unless their estimated life expectancy is $<2$ years or they are unfit or refuse surgery. Adjuvant endocrine therapy significantly decreases the risk of recurrent breast cancer, contralateral breast cancer, and breast-cancer related mortality in both younger and older women. Assessment of the overall health of older women is important to determine the likelihood of cancer vs. non-cancer death. Early discontinuation and non-adherence is prevalent and may be associated with higher rates of mortality. Monitoring and addressing side effects from adjuvant endocrine therapy is important to help decrease early discontinuation of treatment.

\section{References}

1. International agency for research on cancer, WHO, GLOBOCAN 2012: Estimated Cancer Incidence, Mortality and Prevalence Worldwide in 2012, France.

2. National institutes of health, cancer stat fact- Female breast cancer, USA.

3. National cancer institute, SEER cancer statistics review 1975-2011, USA.

4. Schonberg MA, Marcantonio ER, Donglin L, Silliman RA, Ngo L, et al. (2010) Breast cancer among the oldest old: Tumor characteristics, treatment choices, and survival. J Clin Oncol 28: 2038-2045.

5. Molino A, Giovannini M, Auriemma A, Fiorio E, Mercanti A, et al. (2006) Pathological, biological and clinical characteristics, and surgical management, of elderly women with breast cancer. Crit Rev Oncol Hematol 59: 226-233.

6. Wyld L, Garg DK, Kumar ID, Brown H, Reed MW (2004) Stage and treatment variation with age in postmenopausal women with breast cancer: compliance with guidelines. Br J Cancer 90: 1486-1491.

7. Diab SG, Elledge RM, Clark GM (2000) Tumor characteristics and clinical outcome of elderly women with breast cancer. J Natl Cancer Inst 92: 550-556.

8. Crivellari D, Aapro M, Leonard R, Von Minckwitz G, Brain E, et al. (2007) Breast Cancer in the elderly. J Clin Oncol 25: 1882-1890.

9. Daidone MG, Coradini D, Martelli G, Veneroni S (2003) Primary breast cancer in elderly women: Biological profile and relation with clinical outcome. Crit Rev Oncol Hematol 45: 313-325.

10. Ring A, Sestak I, Baum M, Howell A, Buzdar A, et al. (2011) Influence of comorbidities and age on risk of death without recurrence: a retrospective analysis of the arimidex, tamoxifen alone or in combination trial. J Clin Oncol 29: 4266-4272.

11. Bouchardy C, Rapiti E, Fioretta G, Laissue P, Neyroud-Caspar I, et al. (2003) Undertreatment strongly decreases prognosis of breast cancer in elderly women. J Clin Oncol 21: 3580-3587.

12. Van Leeuwen BL, Rosenkranz KM, Feng LL, Bedrosian I, Hartmann K, et al (2011) The effect of under-treatment of breast cancer in women 80 years of age and older. Crit Rev Oncol Hematol 79: 315-320. 
13. Early breast cancer trialists' Collaborative (2002) Comparisons between different polychemotherapy regimens for early breast cancer: Meta-analyses of long-term outcome among 100,Äà000 women in 123 randomised trials. Lancet 379: 432-444.

14. Grunfeld E, Julian JA, Pond G, Maunsell E, Coyle D, et al. (2011) Evaluating survivorship care plans: Results of a randomized, clinical trial of patients with breast cancer. J Clin Oncol 29: 4755-4762.

15. Guth U, Myrick ME, Kandler C, Vetter M (2013) The use of adjuvant endocrine breast cancer therapy in the oldest old. Breast 22: 863-868.

16. Satariano WA, Ragland DR (1994) The effect of comorbidity on 3-year survival of women with primary breast cancer. Ann Intern Med 120: 104-110.

17. Hind D, Wyld L, Reed MW (2007) Surgery, with or without tamoxifen, vs. tamoxifen alone for older women with operable breast cancer: Cochrane review. Br J Cancer 96: 1025-1029.

18. Biganzoli L, Wildiers H, Oakman C, Marotti L, Loibl S, et al. (2012) Management of elderly patients with breast cancer: Updated recommendations of the International Society of Geriatric Oncology (SIOG) and European Society of Breast Cancer Specialists (EUSOMA). Lancet Oncol 13: e148-e160.

19. NCCN Guidelines - Breast Cancer, USA

20. Davies C, Godwin J, Gray R, Clarke M, Cutter D, et al. (2011) Relevance of breas cancer hormone receptors and other factors to the efficacy of adjuvant tamoxifen: Patient-level meta-analysis of randomised trials. Lancet 378: 771-784.

21. Davies C, Pan H, Godwin J, Gray R, Arriagada R, et al. (2013) Long-term effects of continuing adjuvant tamoxifen to 10 years versus stopping at 5 years after diagnosis of oestrogen receptor-positive breast cancer: ATLAS, a randomised trial. Lancet 381: 805-816.

22. Forbes JF, Cuzick J, Buzdar A, Howell A, Tobias JS, et al. (2008) Effect of anastrozole and tamoxifen as adjuvant treatment for early-stage breast cancer: 100-month analysis of the ATAC trial. Lancet Oncology 9: 45-53.

23. Jonat W, Gnant M, Boccardo F, Kaufmann M, Rubagotti A, et al. (2006) Effectiveness of switching from adjuvant tamoxifen to anastrozole in postmenopausal women with hormone-sensitive early-stage breast cancer: a meta-analysis. Lancet Oncology 7: 991-996.

24. Dowsett M, Cuzick J, Ingle J, Coates A, Forbes J, et al. (2010) Meta-analysis of breast cancer outcomes in adjuvant trials of aromatase inhibitors versus tamoxifen. J Clin Oncol 28: 509-518.

25. Mouridsen H, Giobbie-Hurder A, Goldhirsch A, Thurlimann B, Paridaens R, et al. (2009) Letrozole therapy alone or in sequence with tamoxifen in women with breast cancer. N Engl J Med 361: 766-776.

26. Muss HB, Tu D, Ingle JN, Martino S, Robert NJ, et al. (2008) Efficacy, toxicity, and quality of life in older women with early-stage breast cancer treated with letrozole or placebo after 5 years of tamoxifen: NCIC CTG intergroup trial MA.17. J Clin Oncol 26: 1956-1964.

27. Goss PE, Ingle JN, Pritchard KI, Robert NJ, Muss H, et al. (2016) Extending aromatase-inhibitor adjuvant therapy to 10 years. N Engl J Med 375: 209-219.

28. Mamounas EP, Bandos H, Lembersky B, Geyer CE, Jr. Fehrenbacher L, et al. (2016) A randomized, double-blinded, placebo-controlled clinical trial of extended adjuvant endocrine therapy (tx) with letrozole $(L)$ in postmenopausal women with hormone-receptor $(+)$ breast cancer $(B C)$ who have completed previous adjuvant tx with an aromatase inhibitor (Al): Results from NRG Oncology/NSABP B-42. In: San Antonio Breast Conference Symposium. San Antonio, Texas, USA.

29. Tjan-Heijnen VC, Van Hellemond IE, Peer PG, Swinkels AC, Smorenburg CH, et al. (2016) First results from the multicenter phase III DATA study comparing 3 versus 6 years of anastrozole after 2-3 years of tamoxifen in postmenopausal women with hormone receptor-positive early breast cancer. In: San Antonio Breast Cancer Symposium. San Antonio, Texas, USA.

30. Blok E, Velde CJH, Kranenbarg MK, Putter H, Bosch JV et al. (2017) Optimal duration of extended letrozole treatment after 5 years of adjuvant endocrine therapy; results of the randomized phase III IDEAL trial (BOOG 2006-05), Eur Journal of Can 72: S9.

31. Ring A, Sestak I, Baum M, Howell A, Buzdar A, et al. (2011) Influence of comorbidities and age on risk of death without recurrence: A retrospective analysis of the arimidex, tamoxifen alone or in combination trial. J Clin Oncol 29: $4266-4272$
32. Diab SG, Elledge RM, Clark GM (2000) Tumor characteristics and clinical outcome of elderly women with breast cancer. J Natl Cancer Inst 92: 550-556.

33. Land LH, Dalton SO, Jensen MB, Ewertz M (2012) Impact of comorbidity on mortality: A cohort study of 62,591 Danish women diagnosed with early breast cancer, 1990-2008. Breast Cancer Res Treat 131: 1013-1020.

34. Braithwaite D, Satariano WA, Sternfeld B, Hiatt RA, Ganz PA, et al. (2010) Long-term prognostic role of functional limitations among women with breast cancer. J Natl Cancer Inst 102: 1468-1477.

35. Klein DJ, Thorn CF, Desta Z, Flockhart DA, Altman RB, et al. (2013) PharmGKB summary: Tamoxifen pathway, pharmacokinetics. Pharmacogenet Genomics 23: $643-647$.

36. Markopoulos C, Kykalos S, Mantas D (2014) Impact of CYP2D*6 in the adjuvant treatment of breast cancer patients with tamoxifen. World J Clin Oncol 5: 374-381.

37. Antunes MV, Linden R, Santos TV, Wallemacq P, Haufroid V, et al. (2012) Endoxifen levels and its association with CYP2D6 genotype and phenotype: Evaluation of a southern Brazilian population under tamoxifen pharmacotherapy Ther Drug Monit 34: 422-431.

38. Bijl MJ, Van Schaik RH, Lammers LA, Hofman A, Vulto AG, et al. (2009) The CYP2D6*4 polymorphism affects breast cancer survival in tamoxifen users. Breast Cancer Res Treat 118: 125-130.

39. Schroth W, Goetz MP, Hamann U, Fasching PA, Schmidt M, et al. (2009) Association between CYP2D6 polymorphisms and outcomes among women with early stage breast cancer treated with tamoxifen. JAMA 302: 1429-1436.

40. Rae JM, Drury S, Hayes DF, Stearns V, Thibert JN, et al. (2012) CYP2D6 and UGT2B7 genotype and risk of recurrence in tamoxifen-treated breast cancer patients. J Natl Cancer Inst 104: 452-460.

41. Regan MM, Leyland-Jones B, Bouzyk M, Pagani O, Tang W, et al. (2012) CYP2D6 genotype and tamoxifen response in postmenopausal women with endocrine-responsive breast cancer: The breast international group 1-98 trial. J Natl Cancer Inst 104: 441-451.

42. Lien EA, Soiland H, Lundgren S, Aas T, Steen VM, et al. (2013) Serum concentrations of tamoxifen and its metabolites increase with age during steady-state treatment. Breast Cancer Res Treat 141: 243-248.

43. Sheth HR, Lord G, Tkaczuk K, Danton M, Lewis LM, et al. (2003) Aging may be associated with concentrations of tamoxifen and its metabolites in breast cancer patients. J Womens Health (Larchmt) 12: 799-808.

44. Burstein HJ, Prestrud AA, Seidenfeld J, Anderson H, Buchholz TA, et al. (2010) American Society of Clinical Oncology clinical practice guideline: Update on adjuvant endocrine therapy for women with hormone receptor-positive breast cancer. J Clin Oncol 28: 3784-3796.

45. Nightingale G, Hajjar E, Swartz K, Andrel-Sendecki J, Chapman A (2015) Evaluation of a pharmacist-led medication assessment used to identify prevalence of and associations with polypharmacy and potentially inappropriate medication use among ambulatory senior adults with cancer. J Clin Oncol 33 1453-1459.

46. Aubert RE, Stanek EJ, Yao J, Teagarden JR, Subar M, et al. (2009) Risk of breast cancer recurrence in women initiating tamoxifen with CYP2D6 inhibitors. $\mathrm{J}$ Clin Oncol 27.

47. Kelly CM, Juurlink DN, Gomes T, Duong-Hua M, Pritchard KI, et al. (2010) Selective serotonin reuptake inhibitors and breast cancer mortality in women receiving tamoxifen: a population based cohort study. BMJ 340: c693.

48. Sideras K, Ingle JN, Ames MM, Loprinzi CL, Mrazek DP, et al. (2010) Coprescription of tamoxifen and medications that inhibit CYP2D6. J Clin Oncol 28: 2768-2776.

49. Lodwick R, McConkey B, Brown AM, (1987) Life threatening interaction between tamoxifen and warfarin. Br Med J (Clin Res Ed) 295: 1141.

50. Tenni P, Lalich DL, Byrne MJ, (1989) Life threatening interaction between tamoxifen and warfarin. BMJ 298: 93.

51. Osborne CK, (1998) Tamoxifen in the treatment of breast cancer. N Engl J Med 339: $1609-1618$.

52. Smith IE, Dowsett M (2003) Aromatase inhibitors in breast cancer. N Engl J Med 348: 2431-2442

53. Lonning P, Pfister C, Martoni A, Zamagni C (2003) Pharmacokinetics of thirdgeneration aromatase inhibitors. Semin Oncol 30: 23-32. 
54. Coombes RC, Hall E, Gibson LJ, Paridaens R, Jassem J, et al. (2004) A randomized trial of exemestane after two to three years of tamoxifen therapy in postmenopausal women with primary breast cancer. N Engl J Med 350: 1081-1092.

55. Coates AS, Keshaviah A, Thurlimann B, Mouridsen H, Mauriac L, et al. (2007) Five years of letrozole compared with tamoxifen as initial adjuvant therapy for postmenopausal women with endocrine-responsive early breast cancer: update of study BIG 1-98. J Clin Oncol 25: 486-492.

56. Shapiro CL, Recht A (2001) Side effects of adjuvant treatment of breast cancer. N Engl J Med 344: 1997-2008.

57. Love RR, Cameron L, Connell BL, Leventhal H (1991) Symptoms associated with tamoxifen treatment in postmenopausal women. Arch Intern Med 151: 1842-1847.

58. Howell A, Cuzick J, Baum M, Buzdar A, Dowsett M, et al. (2005) Results of the ATAC (arimidex, tamoxifen, alone or in combination) trial after completion of 5 years' adjuvant treatment for breast cancer. Lancet 365: 60-62.

59. Trinkaus M, Chin S, Wolfman W, Simmons C, Clemons M (2008) Should urogenital atrophy in breast cancer survivors be treated with topical estrogens? Oncologist 13: 222-231.

60. Meier CR, Jick H (1998) Tamoxifen and risk of idiopathic venous thromboembolism. Br J Clin Pharmacol 45: 608-612.

61. Grey AB, Stapleton JP, Evans MC, Reid IR (1995) The effect of the antiestrogen tamoxifen on cardiovascular risk factors in normal postmenopausal women. J Clin Endocrinol Metab 80: 3191-3195.

62. Presant CA, Bosserman L, Young T, Vakil M, Horns R, et al. (2007) Aromatase inhibitor-associated arthralgia and/or bone pain: Frequency and characterization in non-clinical trial patients. Clin Breast Cancer 7: 775-778.

63. Henry NL, Giles JT, Ang D, Mohan M, Dadabhoy D, et al. (2008) Prospective characterization of musculoskeletal symptoms in early stage breast cancer patients treated with aromatase inhibitors. Breast Cancer Res Treat 111: 365-372.

64. Sestak I, Cuzick J, Sapunar F, Eastell R, Forbes JF, et al. (2008) Risk factors for joint symptoms in patients enrolled in the ATAC trial: A retrospective, exploratory analysis. Lancet Oncol 9: 866-872.

65. Mieog JS, Morden JP, Bliss JM, Coombes RC, Van De Velde CJ, (2012) Carpal tunnel syndrome and musculoskeletal symptoms in postmenopausal women with early breast cancer treated with exemestane or tamoxifen after 2-3 years of tamoxifen: A retrospective analysis of the Intergroup Exemestane Study. Lancet Oncology 13: 420-432.

66. Goss PE, Ingle JN, Pritchard KI, Ellis MJ, Sledge GW, et al. (2013) Exemestane versus anastrozole in postmenopausal women with early breast cancer: $\mathrm{NCIC}$ CTG MA.27--a randomized controlled phase III trial. J Clin Oncol 31: 1398-1404.

67. Cuzick J, Sestak I, Baum M, Buzdar A, Howell A, et al. (2010) Effect of anastrozole and tamoxifen as adjuvant treatment for early-stage breast cancer: 10-year analysis of the ATAC trial. Lancet Oncology 11: 1135-1141.

68. Cooke AL, Metge C, Lix L, Prior HJ, Leslie WD, (2008) Tamoxifen use and osteoporotic fracture risk: A population-based analysis. J Clin Oncol 26: 5227-5232.

69. Fenlon DR, Corner JL, Haviland JS (2008) A randomized controlled trial of relaxation training to reduce hot flashes in women with primary breast cancer. J Pain Symptom Manage 35: 397-405

70. Duijts SFA, Van Beurden M, Oldenburg HSA, Hunter MS, Kieffer JM, et al. (2012) Efficacy of cognitive behavioral therapy and physical exercise in alleviating treatment-induced menopausal symptoms in patients with breas cancer: Results of a randomized, controlled, multicenter trial. J Clin Oncol 30: 4124-4133.

71. Daley A, MacArthur C, Mutrie N, Stokes-Lampard H (2007) Exercise for vasomotor menopausal symptoms. Cochrane Database Syst Rev CD006108.

72. Rossouw JE, Anderson GL, Prentice RL, LaCroix AZ, Kooperberg C, et al (2002) Risks and benefits of estrogen plus progestin in healthy postmenopausal women: Principal results from the women's health initiative randomized controlled trial. JAMA 288: 321-333.

73. Rada G, Capurro D, Pantoja T, Corbalan J, Moreno G, et al. (2010) Nonhormonal interventions for hot flushes in women with a history of breast cancer. Cochrane Database Syst Rev 9: CD004923.

74. Loprinzi CL, Sloan J, Stearns V, Slack R, lyengar M, et al. (2009) Newer antidepressants and gabapentin for hot flashes: An individual patient pooled analysis. J Clin Oncol 27: 2831-2837.
75. Barton DL, LaVasseur BI, Sloan JA, Stawis AN, Flynn KA, et al. (2010) Phase III, placebo-controlled trial of three doses of citalopram for the treatment of hot flashes: NCCTG Trial N05C9. J Clin Oncol 28: 3278-3283.

76. Pandya KJ, Raubertas RF, Flynn PJ, Hynes HE, Rosenbluth RJ, et al. (2000) Oral clonidine in postmenopausal patients with breast cancer experiencing tamoxifen-induced hot flashes: A University of Rochester Cancer Center Community Clinical Oncology Program study. Ann Intern Med 132: 788-793.

77. Pandya KJ, Morrow GR, Roscoe JA, Zhao H, Hickok JT, et al. (2005) Gabapentin for hot flashes in 420 women with breast cancer: A randomised double-blind placebo-controlled trial. Lancet 366: 818-824.

78. Loprinzi CL, Qin R, Baclueva EP, Flynn KA, Rowland KM, et al. (2010) Phase III, randomized, double-blind, placebo-controlled evaluation of pregabalin for alleviating hot flashes, N07C1. J Clin Oncol 28: 641-647.

79. Bordeleau L, Pritchard KI, Loprinzi CL, Ennis M, Jugovic O, et al. (2010) Multicenter, randomized, cross-over clinical trial of venlafaxine versus gabapentin for the management of hot flashes in breast cancer survivors. $J$ Clin Oncol 28: 5147-5152.

80. Boekhout AH, Vincent AD, Dalesio OB, Van Den Bosch J, Foekema-Töns JH et al. (2011) Management of hot flashes in patients who have breast cancer with venlafaxine and clonidine: a randomized, double-blind, placebo-controlled trial. J Clin Oncol 29: 3862-3868.

81. Chin SN, Trinkaus M, Simmons C, Flynn C, Dranitsaris G, et al. (2009) Prevalence and severity of urogenital symptoms in postmenopausal women receiving endocrine therapy for breast cancer. Clin Breast Cancer 9: 108-117.

82. Moegele M, Buchholz S, Seitz S, Ortmann O (2012) Vaginal estrogen therapy in postmenopausal breast cancer patients treated with aromatase inhibitors. Arch Gynecol Obstet 285: 1397-1402.

83. Leiblum S, Bachmann G, Kemmann E, Colburn D, Swartzman L (1983) Vaginal atrophy in the postmenopausal woman. The importance of sexual activity and hormones. JAMA 249: 2195-2198.

84. Sinha A, Ewies AA (2013) Non-hormonal topical treatment of vulvovaginal atrophy: An up-to-date overview. Climacteric 16: 305-312.

85. Suckling J, Lethaby A, Kennedy R (2003) Local oestrogen for vaginal atrophy in postmenopausal women. Cochrane Database Syst Rev: CD001500.

86. Simmons CE, Kuchuk I, Freedman OC, Colgan T, Dodd A, et al. (2012) Are estring and vagifem equally effective and safe for the treatment of urogenital atrophy in breast cancer patients on aromatase inhibitor therapy? Clin Oncol (R Coll Radiol) 24: e128-e129.

87. Pruthi S, Simon JA, Early AP (2011) Current overview of the management of urogenital atrophy in women with breast cancer. Breast J 17: 403-408.

88. Dew JE, Wren BG, Eden JA (2003) A cohort study of topical vaginal estrogen therapy in women previously treated for breast cancer. Climacteric 6: 45-52.

89. Fung MF, Reid A, Faught W, Le T, Chenier C, et al. (2003) Prospective longitudinal study of ultrasound screening for endometrial abnormalities in women with breast cancer receiving tamoxifen. Gynecol Oncol 91: 154-159.

90. Bertelli G, Venturini M, Del Mastro L, Garrone O, Cosso M, et al. (1998) Tamoxifen and the endometrium: Findings of pelvic ultrasound examination and endometrial biopsy in asymptomatic breast cancer patients. Breast Cancer Res Treat 47: 41-46.

91. Committee Opinion No. 60 (2014) Tamoxifen and uterine cancer. Obstet Gynecol 123: 1394-1397.

92. Leibson CL, Tosteson AN, Gabriel SE, Ransom JE, Melton LJ, (2002) Mortality, disability, and nursing home use for persons with and without hip fracture: a population-based study. J Am Geriatr Soc 50: 1644-1650.

93. Hillner BE, Ingle JN, Chlebowski RT, Gralow J, Yee GC, et al. (2003) American society of clinical oncology 2003 update on the role of bisphosphonates and bone health issues in women with breast cancer. J Clin Oncol 21: 4042-4057.

94. Reid DM, Doughty J, Eastell R, Heys SD, Howell A, et al. (2008) Guidance for the management of breast cancer treatment-induced bone loss: A consensus position statement from a UK Expert Group. Cancer Treat Rev 34: S3-S18.

95. Kannus P, Uusi-Rasi K, Palvanen M, Parkkari J (2005) Non-pharmacological means to prevent fractures among older adults. Ann Med 37: 303-310.

96. Coleman RE, Bolten WW, Lansdown M, Dale S, Jackisch C, et al. (2008) Aromatase inhibitor-induced arthralgia: Clinical experience and treatment recommendations. Cancer Treat Rev 34: 275-282. 
Citation: Hsu T, Sud S (2017) Endocrine Therapy in Older Women with Early-Stage Hormone Sensitive Breast Cancer. J Gerontol Geriatr Res 6: 440. doi:10.4172/2167-7182.1000440

Page 8 of 8

97. Younus J, Kligman L (2010) Management of aromatase inhibitor-induced arthralgia. Curr Oncol 17: 87-90.

98. Niravath $P$ (2013) Aromatase inhibitor-induced arthralgia: a review. Ann Oncol 24: $1443-1449$

99. Crew KD, Capodice JL, Greenlee H, Brafman L, Fuentes D, et al. (2010) Randomized, blinded, sham-controlled trial of acupuncture for the management of aromatase inhibitor-associated joint symptoms in women with early-stage breast cancer. J Clin Oncol 28: 1154-1160.

100. Covered, randomized trial of exercise vs usual care on aromatase inhibitorassociated arthralgias in women with breast cancer. 2013 San Antonio Breas Cancer Symposium, USA.

101.Chlebowski RT (2009) Aromatase inhibitor-associated arthralgias. J Clin Oncol 27: 4932-4934.

102. Henry NL, Giles JT, Stearns V (2008) Aromatase inhibitor-associated musculoskeletal symptoms: Etiology and strategies for management. Oncology (Williston Park) 22: 1401-1408.

103. Thorne C (2007) Management of arthralgias associated with aromatase inhibitor therapy. Curr Oncol 14: S11-S19.

104. Iwata H, Masuda N, Ohno S, Rai Y, Sato Y, et al. (2013) A randomized, double-blind, controlled study of exemestane versus anastrozole for the firstline treatment of postmenopausal Japanese women with hormone-receptorpositive advanced breast cancer. Breast Cancer Res Treat 139: 441-451.

105. Briot K, Tubiana-Hulin M, Bastit L, Kloos I, Roux C (2010) Effect of a switch of aromatase inhibitors on musculoskeletal symptoms in postmenopausal women with hormone-receptor-positive breast cancer: The ATOLL (articular tolerance of letrozole) study. Breast Cancer Res Treat 120: 127-134.

106. Balkrishnan R (1998) Predictors of medication adherence in the elderly. Clin Ther 20: 764-771.

107. Extermann M, (2005) Older patients, cognitive impairment, and cancer: An increasingly frequent trial. J Natl Compr Canc Netw 3: 593-596.

108. Extermann M (2007) Interaction between comorbidity and cancer. Cancer Control 14: 13-22.

109. Hershman DL, Kushi LH, Shao T, Buono D, Kershenbaum A, et al. (2010) Early discontinuation and nonadherence to adjuvant hormonal therapy in a cohort of 8,769 early-stage breast cancer patients. J Clin Oncol 28: 4120-4128.

110. Kimmick G, Anderson R, Camacho F, Bhosle M, Hwang W, et al. (2009) Adjuvant hormonal therapy use among insured, low-income women with breast cancer. J Clin Oncol 27: 3445-3451.
111. Sheppard VB, Faul LA, Luta G, Clapp JD, Yung RL, et al. (2014) Frailty and adherence to adjuvant hormonal therapy in older women with breast cancer: CALGB protocol 369901. J Clin Oncol 32: 2318-2327.

112. Satariano WA, Ragland DR (1994) The effect of comorbidity on 3-year survival of women with primary breast cancer. Ann Intern Med 120: 104-110.

113. Hershman DL, Shao T, Kushi LH, Buono D, Tsai WY, et al. (2011) Early discontinuation and non-adherence to adjuvant hormonal therapy are associated with increased mortality in women with breast cancer. Breast Cancer Res Treat 126: 529-537.

114. Partridge AH, Wang PS, Winer EP, Avorn J (2003) Nonadherence to adjuvant tamoxifen therapy in women with primary breast cancer. J Clin Oncol 21: 602-606.

115. Neugut Al, Subar M, Wilde ET, Stratton S, Brouse CH, et al. (2011) Association between prescription co-payment amount and compliance with adjuvant hormonal therapy in women with early-stage breast cancer. J Clin Oncol 29 : 2534-2542.

116. Hershman DL, Tsui J, Meyer J, Glied S, Hillyer GC, et al. (2014) The change from brand-name to generic aromatase inhibitors and hormone therapy adherence for early-stage breast cancer. J Natl Cancer Inst 106.

117. Owusu C, Buist DS, Field TS, Lash TL, Thwin SS, et al. (2008) Predictors of tamoxifen discontinuation among older women with estrogen receptor-positive breast cancer. J Clin Oncol 26: 549-555.

118. Murphy CC, Bartholomew LK, Carpentier MY, Bluethmann SM, Vernon SW (2012) Adherence to adjuvant hormonal therapy among breast cancer survivors in clinical practice: a systematic review. Breast Cancer Res Treat 134: 459-478.

119. Partridge AH, LaFountain A, Mayer E, Taylor BS, Winer E, et al. (2008) Adherence to initial adjuvant anastrozole therapy among women with earlystage breast cancer. J Clin Oncol 26: 556-562.

120.Sedjo RL, Devine S (2011) Predictors of non-adherence to aromatase inhibitors among commercially insured women with breast cancer. Breast Cancer Res Treat 125: 191-200.

121. Hughes KS, Schnaper LA, Bellon JR, Cirrincione CT, Berry DA, et al. (2013) Lumpectomy plus tamoxifen with or without irradiation in women age 70 years or older with early breast cancer: Long-term follow-up of CALGB 9343. J Clin Oncol 31: 2382-2387.

122. Clarke M, Collins R, Darby S, Davies C, Elphinstone P, et al. (2005) Effects of radiotherapy and of differences in the extent of surgery for early breast cancer on local recurrence and 15-year survival: An overview of the randomised trials. Lancet 366: 2087-2106. 